\title{
THE EFFECT OF BRAND EQUITY, PROMOTION AND SERVICES ON CUSTOMER'S DECISION TO USE SHARIA BANK IN SANGKUMPAL BONANG PADANGSIDIMPUAN MARKET
}

\author{
Jeni Kurnia ${ }^{1}$, Muhammad Isa ${ }^{2}$, Budi Gautama Siregar ${ }^{3}$, Damri Batubara ${ }^{4}$ \\ ${ }^{1}$ IAIN Padangsidimpuan (Ekonomi Syariah, FEBI, IAIN Padangsidimpuan) \\ ${ }^{2}$ IAIN Padangsidimpuan (Perbankan Syariah, FEBI, IAIN Padangsidimpuan) \\ ${ }^{2}$ IAIN Padangsidimpuan (Perbankan Syariah, FEBI, IAIN Padangsidimpuan) \\ ${ }^{4}$ IAIN Padangsidimpuan (Perbankan Syariah, FEBI, IAIN Padangsidimpuan) \\ jenikuarnia@gmail.com ${ }^{1}$, muhammadisa@iain-padangsidimpuan.ac.id ${ }^{2}$, budigautamasiregar@iain- \\ padangsidimpuan.ac.id ${ }^{3}$ damribatubara@iain-padangsidimpuan.ac.id ${ }^{4}$
}

\begin{abstract}
ABSTRAK
Pasar Sangkumpal Bonang sama dengan pasar pada umumnya, dimana pasar ini tempat orang berniaga, mencari rezeki, tempat bertemunya penjual dan pembeli dan melakukan transaksi. Berdasarkan data yang diperoleh pedagang Pasar Sangkumpal Bonang Padangsidimpuan lebih banyak yang menggunakan Bank Konvensional daripada Bank Syariah. Penelitian ini bertujuan untuk Mengetahui Pengaruh Ekuitas Merek, Promosi Dan Pelayanan Terhadap Keputusan Nasabah Menggunakan Bank Syariah Di Pasar Sangkumpal Bonang Padangsidimpuan. Penelitian ini merupakan penelitin kuantitatif, sumber data yang digunakan adalah data primer. Teknik pengumpulan data yang digunakan adalah angket, dan dokumentasi dengan jumlah sampel 69 responden dengan teknik pengukuran sampelnya adalah rumus slovin. Hasil penelitian secara parsial (uji t) adalah Ekuitas Merek dan Pelayanan berpengaruh terhadap Keputusan Nasabah sedangkan Promosi tidak berpengaruh terhadap Keputusan Nasabah.
\end{abstract}

Kata Kunci: Ekuitas Merek, Promosi, Pelayanan, Keputusan Nasabah

\begin{abstract}
Sangkumpal Bonang market is the same as the market in general, where this market is where people trade, looking for fortune, a place where sellers and buyers meet and conduct transactions. Based on data obtained by Sangkumpal Bonang Padangsidimpuan market, more traders use conventional banks than sharia banks. This study aims to determine the effect of brand equity, promotion and service on customer decisions using Islamic banks in the Sangkumpal Bonang Padangsidimpuan market. This research is a quantitative research, data sources used are primary data. The data collection technique used was a questionnaire, and documentation with a total sample of 69 respondents with the sample measurement technique was the Slovin formula. The results of partial research ( $t$ test) are Brand Equity and Services affect the Customer Decision while Promotion does not affect the Customer Decision.
\end{abstract}

Keywords: Brand Equity, Promotion, Service, Customer Decision 


\section{A. PENDAHULUAN}

Bank syariah merupakan lembaga keuangan yang beroperasional sesuai dengan prinsip-prinsip syariah atau peraturan yang ada dalam syariat Islam. Bank berdasarkan prinsip syariah atau bank Islam, seperti halnya bank konvensional, juga berfungsi sebagai suatu lembaga intermediasi (itermediatery institution), yaitu mengarahkan dana dari pihak masyarakat dan menyalurkan kembali danadana tersebut kepada masyarakat yang membutuhkan dalam bentuk fasilitas pembiayaan. Bedanya hanyalah bahwa bank syariah melakukan kegiatan usahanya tidak berdasarkan bunga atau bebas bunga (interest free), tetapi berdasarkan pembagian keuntungan dan kerugian (profit and loss sharing principle atau PLS principle).

Di dalam perbankan, keputusan nasabah juga merupakan hal yang penting. Keputusan nasabah adalah hal sesuatu yang diputuskan konsumen untuk memutuskan pilihan atas tindakan pembelian barang atau jasa atau suatu keputusan setelah melalui beberapa proses yaitu pengenalan kebutuhan, pencarian informasi, dan melakukan evaluasi alternatif yang menyebabkan timbulnya keputusan.

Penelitian ini dilakukan di Pasar Sangkumpal Bonang Padangsidimpuan, karena pasar ini terletak di pusat kota Padangsidimpuan dan dekat dengan Bank-Bank Konvensional maupun Bank Syariah. Pasar
Sangkumpal Bonang sama dengan pasar pada umumnya, dimana pasar ini tempat orang berniaga, mencari rezeki, tempat bertemunya penjual dan pembeli dan melakukan transaksi. Berikut adalah jumlah data Pedagang Pasar Sangkumpal Bonang Padangsidimpuan yang menggunakan Bank Syariah:

Tabel 1

Jumlah Pedagang Di Pasar Sangkumpal Bonang Padangsidimpuan Yang Menggunakan Bank Syariah Tahun 2018

\begin{tabular}{|c|c|c|c|c|}
\hline Tahun & $\begin{array}{c}\text { Bank } \\
\text { Syariah }\end{array}$ & $\begin{array}{c}\text { Bank } \\
\text { Konvensional }\end{array}$ & $\begin{array}{c}\text { Tidak } \\
\text { Menggunakan } \\
\text { Bank } \\
\text { Konvensional }\end{array}$ & Total \\
\hline 2019 & 220 & 402 & 248 & 870 \\
\hline
\end{tabular}

Sumber: Pengelola Pasar Sangkumpal Bonang Padangsidimpuan

Dari data di atas dapat dilihat kebanyakan Pedagang Sangkumpal Bonang menabung di Bank Konvensional. Setelah melakukan survey langsung peneliti memperoleh data pedagang yang menabung di Bank Syariah sebanyak 220 pedagang, yang menabung di Bank Konvensional 402 pedagang dan yang tidak menggunakan Bank sama sekali sebanyak 248 pedagang.

Dari data didapat peneliti dapat dilihat masih banyak yang menabung di Bank Konvensional, padahal mayoritas pedagang di Pasar Sangkumpal Bonang adalah muslim. Penyebabnya adalah mereka mengatakan bahwa Bank Syariah dan Bank Konvensional sama saja, hanya labelnya saja yang syariah, alasan mereka mengatakan sama karena dalam bentuk pinjaman dana di Bank Syariah angsuran 
per bulan atau marginnya tidak ditentukan di awal, tetapi berdasarkan berapa pendapatan yang diterima nasabah, namun itu hanya sekedar teori praktek yang terjadi berbanding terbalik.

Dari fenomena di atas maka peneliti tertarik mengambil judul mengenai "Pengaruh Ekuitas Merek, Promosi Dan Pelayanan Terhadap Keputusan Nasabah Menggunakan Bank Syariah Di Pasar Sangkumpal Bonang Padangsidimpuan".

\section{B. METODE}

Penelitian ini dilakukan di Pasar Sangkumpal Bonang Padangsidimpuan yang terletak di kelurahan Wek II, Padangsidimpuan Utara, Kota Padangsidimpuan, Sumatera utara 22711. Penelitian ini merupakan penelitian kuantitatif dengan menggunakan data primer dan data sekunder. Pengumpulan data dilakukan dengan angket dan dokumentasi, sedangkan sampel diambil dengan teknik accidental sampling berjumlah 69 pedagang yang diperoleh dengan rumus slovin. Teknik analisis data yaitu uji asumsi klasik, analisis regresi linear berganda, koefisien determinasi, dan uji hipotesis.

\section{HASIL DAN PEMBAHASAN}

1. Uji Instrumen

a) Uji Validitas

Validitas adalah indeks yang menunjukkan sejauh mana suatu alat pengukur benar-benar mengukur apa yang akan diukur. Suatu skala pengukuran disebut valid apabila ia melakukan apa yang seharusnya diukur. Uji validitas berguna untuk mengetahui apakah ada pertanyaan atau pernyataan pada kuesioner yang harus diganti karena dianggap tidak relevan. Untuk melakukan uji validitas peneliti menggunakan sampel $(n=69)$ responden dengan rtabel adalah 0,1997 .

a. Uji Validitas Variabel Keputusan Nasabah

Tabel 2

Hasil Uji Validitas Keputusan Nasabah

\begin{tabular}{|c|c|c|c|}
\hline $\begin{array}{c}\text { Item } \\
\text { Pertanyaan }\end{array}$ & $r_{\text {hitung }}$ & $r_{\text {tabel }}$ & Keterangan \\
\hline KN_1 & 0,332 & \multirow{10}{*}{$\begin{array}{l}\text { Instrumen valid, jika } \\
r_{\text {hitung }}>r_{\text {tabel }} \text { dengan df } \\
=\text { pada taraf } \\
\text { signifikan } 10 \% \\
\text { sehingga diperoleh } \\
r_{\text {tabel }}=0,1997\end{array}$} & Valid \\
\hline KN_2 & 0,676 & & Valid \\
\hline KN_3 & 0,282 & & Valid \\
\hline KN_4 & 0,602 & & Valid \\
\hline KN_5 & 0,542 & & Valid \\
\hline KN_6 & 0,401 & & Valid \\
\hline KN_7 & 0,674 & & Valid \\
\hline KN_8 & 0,612 & & Valid \\
\hline KN_9 & 0,338 & & Valid \\
\hline KN_10 & 0,548 & & Valid \\
\hline
\end{tabular}

Sumber: Data diolah, SPSS 23 Tahun 2019

b) Uji Validitas Variabel Ekuitas Merek Tabel 3

Hasil Uji Validitas Ekuitas Merek

\begin{tabular}{|c|c|c|c|}
\hline $\begin{array}{c}\text { Item } \\
\text { Pertanyaan }\end{array}$ & $r_{\text {hitung }}$ & $r_{\text {tabel }}$ & $\begin{array}{c}\text { Keteranga } \\
n\end{array}$ \\
\hline EM_1 & 0,627 & \multirow{3}{*}{$\begin{array}{c}\text { Instrumen } \\
\text { valid, jika } \\
r_{\text {hitung }}>r_{\text {tabel }} \\
\text { dengan } d f= \\
\text { pada taraf }\end{array}$} & Valid \\
\hline EM_2 & 0, 397 & & Valid \\
\hline EM_3 & 0,650 & & Valid \\
\hline
\end{tabular}


POINT Vol. 1, No. 2, Des 2020

\begin{tabular}{|c|c|c|c|}
\hline EM_4 & 0,736 & \multirow{6}{*}{$\begin{array}{l}\text { signifikan } 10 \% \\
\text { sehingga } \\
\text { diperoleh } r_{\text {tabel }} \\
=0,1997\end{array}$} & Valid \\
\hline EM_5 & 0,567 & & Valid \\
\hline EM_6 & 0,595 & & Valid \\
\hline EM_7 & 0,523 & & Valid \\
\hline EM_8 & 0,740 & & Valid \\
\hline EM_9 & 0,591 & & Valid \\
\hline EM_ 10 & 0,523 & & \\
\hline
\end{tabular}

Sumber: Data diolah, SPSS 23 Tahun 2019

c) Uji Validitas Variabel Promosi

Tabel 4

Hasil Uji Validitas Promosi

\begin{tabular}{|c|c|c|c|}
\hline $\begin{array}{c}\text { Item } \\
\text { Pertanyaan }\end{array}$ & $r_{\text {hitung }}$ & $r_{\text {tabel }}$ & Keterangan \\
\hline Pr_1 & 0,310 & \multirow{7}{*}{$\begin{array}{c}\text { Instrumen } \\
\text { valid, jika } \\
r_{\text {hitung }}>r_{\text {tabel }} \\
\text { dengan df = } \\
\text { pada taraf } \\
\text { signifikan10\% } \\
\text { sehingga } \\
\text { diperoleh } r_{\text {tabel }} \\
=0,1997\end{array}$} & Valid \\
\hline Pr_2 & 0,583 & & Valid \\
\hline Pr_3 & 0,747 & & Valid \\
\hline Pr_4 & 0,603 & & Valid \\
\hline Pr_5 & 0,718 & & Valid \\
\hline Re_6 & 0,365 & & Valid \\
\hline Pr_7 & 0,576 & & Valid \\
\hline $\operatorname{Pr} 8$ & 0,656 & & \\
\hline
\end{tabular}

Sumber: Data diolah, SPSS 23 Tahun 2019

d) Uji Validitas Variabel Pelayanan

Tabel 5

Hasil Uji Validitas Pelayanan

\begin{tabular}{|c|c|c|c|}
\hline $\begin{array}{c}\text { Item } \\
\text { Pertanyaan }\end{array}$ & $r_{\text {hitung }}$ & $r_{\text {tabel }}$ & Keterangan \\
\hline PL_1 & 0,734 & \multirow{5}{*}{$\begin{array}{c}\text { Instrumen } \\
\text { valid, jika } \\
r_{\text {hitung }}>r_{\text {tabel }} \\
\text { dengan df = } \\
\text { pada taraf } \\
\text { signifikan10\% } \\
\text { sehingga } \\
\text { diperoleh }\end{array}$} & Valid \\
\hline PL_2 & 0,269 & & Valid \\
\hline PL_3 & 0,499 & & Valid \\
\hline PL_4 & 0,488 & & Valid \\
\hline PL_5 & 0,734 & & Valid \\
\hline
\end{tabular}

\begin{tabular}{|c|c|c|c|}
\hline PL_6 & 0,719 & \multirow{2}{*}{$\begin{array}{c}\text { rtabel }= \\
0,1997\end{array}$} & Valid \\
\cline { 1 - 1 } & & & Valid \\
\hline PL_7 & 0,740 & & Valid \\
\hline PL_8 & 0,356 & & Valid \\
\hline PL_9 & 0,371 & & \\
\hline
\end{tabular}

Sumber: Data diolah, SPSS 23 Tahun 2019

e) Reliabilitas

Suatu instrumen pengumpulan data dikatakan reliabel jika pengukurannya konsisten dan akurat. Jadi, uji reliabilitas instrumen sebagai alat ukur sehingga hasil pengukuran dapat dipercaya.

Tabel 6

Hasil Olah data SPSS Versi 23 Uji Reliabilitas

\begin{tabular}{|c|c|c|c|c|}
\hline Variabel & $\begin{array}{l}\text { Cronbac } \\
\text { h's Alpha }\end{array}$ & Ketentuan & $\begin{array}{c}\text { Keterang } \\
\text { an }\end{array}$ & $\begin{array}{l}\mathrm{N} \text { of } \\
\text { Item }\end{array}$ \\
\hline $\begin{array}{l}\text { Keputusan } \\
\text { Nasabah (Y) }\end{array}$ & 0,671 & \multirow{4}{*}{$\begin{array}{c}\text { Instrumen } \\
\text { reliabel, } \\
\text { jika } \\
\text { Cronbach's } \\
\text { Alpha > } \\
0,6 .\end{array}$} & Reliabel & 10 \\
\hline $\begin{array}{l}\text { Ekuitas } \\
\text { Merek (X1) }\end{array}$ & 0,800 & & Reliabel & 10 \\
\hline Promosi (X2) & 0,683 & & Reliabel & 8 \\
\hline $\begin{array}{l}\text { Pelayanan } \\
\text { (X3) }\end{array}$ & 0,692 & & Reliabel & 9 \\
\hline
\end{tabular}

Berdasarkan tabel di atas menunjukkan nilai cronbach alpha dari masing-masing variabel lebih besar dari 0,6. Sebagaimana yang dijelaskan diatas maka dibuat kesimpulan instrumen masing-masing variabel dinyatakan reliabel.

2. Uji Asumsi Klasik

a) Uji Multikolinearitas

Uji multikolinearitas adalah untuk melihat ada tidaknya korelasi yang tinggi antara variable 
independen dalam suatu model regresi linear berganda.

Tabel 8

Hasil Olah data SPSS Versi 23 Uji

Multikolineritas

Coefficientsa

\begin{tabular}{|c|c|c|c|c|}
\hline \multirow[b]{2}{*}{ Model } & \multirow[b]{2}{*}{$\mathrm{t}$} & \multirow[b]{2}{*}{ Sig. } & \multicolumn{2}{|c|}{$\begin{array}{c}\text { Collinearity } \\
\text { Statistics }\end{array}$} \\
\hline & & & $\begin{array}{c}\text { Toleranc } \\
\mathrm{e}\end{array}$ & VIF \\
\hline (Constant) & 2,021 & ,048 & & \\
\hline EM & 5,120 & ,000 & 862 & 1,160 \\
\hline PR & ,890 & 377 & 903 & 1,107 \\
\hline PL & 2,237 & ,029 & ,926 & 1,080 \\
\hline
\end{tabular}

Sumber: hasil output SPSS versi 23 , data diolah

Berdasarkan hasil pengujian multikolinearitas di atas, diketahui bahwa nilai dari variance inflation factor (VIF) dari X1= 1,160 X2=1,107 X3=1,080yakni kurang dari 10 dan tolerance dari $\times 1=0,862 \times 2=0,903, \times 3=$ 0,926 lebih besar dari 0,1. Sehingga dapat disimpulkan bahwa variabel Ekuitas Merek (X1), promosi (X2), Pelayanan (X3) tidak terjadi persoalan multikolinearitas.

b) Uji autokerelasi

Uji autokorelasi digunakan untuk mengetahui ada atau tidaknya penyimpangan asumsi klasik autokorelasi, yaitu adanya ketidaksamaan varian dari residual untuk semua pengamatan pada model regresi.

Tabel 9

Hasil Olah Data SPSS Versi 23Uji Autokorelasi Model Summaryb

\begin{tabular}{|c|c|r|r|r|}
\hline Model & R & R Square & $\begin{array}{c}\text { Adjusted R } \\
\text { Square }\end{array}$ & $\begin{array}{c}\text { Durbin- } \\
\text { Watson }\end{array}$ \\
\hline 1 &, $651 \mathrm{a}$ &, 424 &, 397 & 1,850 \\
\hline
\end{tabular}

a. Predictors: (Constant), PL, PR, EM

b. Dependent Variable: KN

Sumber: hasil output SPSS versi 23 , data diolah
Berdasarkan tabel hasil output diatas nilai Durbin Watson sebesar 1,850 artinya lebih besar dari -2 dan lebih kecil dari $+2(-2<1,837<+2)$. Sehingga tidak terjadi Auokorelasi.

c) Koefisien Determinasi (R2)

Nilai koefisien determinasi R2 menunjukkan presentase pengaruh semua variable independen terhadap variable dependen.

Tabel 10

Hasil Olah Data SPSS Versi 23 Uji Koefisien

Determinasi

Model Summaryb

\begin{tabular}{|c|c|c|c|r|}
\hline Model & $\mathrm{R}$ & $\begin{array}{c}\mathrm{R} \\
\text { Square }\end{array}$ & $\begin{array}{c}\text { Adjusted R } \\
\text { Square }\end{array}$ & $\begin{array}{c}\text { Std. Error of } \\
\text { the Estimate }\end{array}$ \\
\hline 1 &, $651 \mathrm{a}$ &, 424 &, 397 & 2,387 \\
\hline
\end{tabular}

a. Predictors: (Constant), PL, PR, EM

b. Dependent Variable: KN

Sumber: hasil output SPSS versi 23, data diolah Dari hasil output diatas diperoleh nilai adjust R Square sebesar 0,397. Artinya persentasi sumbangan pengaruh Ekuitas merek, promosi dan pelayanan terhadap keputusan nasabah sebasar $39,7 \%$. Sedangkan sisanya sebesar $60,3 \%$ dipengaruhi oleh variabel lain yang tidak dicantumkan pada penelitian ini.

\section{Analisis Regresi Linear Berganda}

Uji ini digunakan untuk mengetahui pengaruh secara linier antara empat variabel independen dengan satu variabel dependen.

Tabel 11

Hasil Olah Data SPSS Versi 23 Analisis Regresi Berganda

Coefficientsa

\begin{tabular}{|c|r|r|r|r|r|}
\hline \multirow{2}{*}{ Model } & \multicolumn{2}{|c|}{$\begin{array}{c}\text { Unstandardized } \\
\text { Coefficients }\end{array}$} & $\begin{array}{c}\text { Standardized } \\
\text { Coefficients }\end{array}$ & & \\
\cline { 2 - 4 } & \multicolumn{1}{|c|}{ B } & Std. Error & \multicolumn{1}{|c|}{ Beta } & \multicolumn{1}{c|}{ T } & Sig. \\
\hline (Constant) & 10,762 & 5,326 & & 2,021 &, 048 \\
EM &, 485 &, 095 &, 523 & 5,120 &, 000 \\
PR &, 113 &, 128 &, 089 &, 890 &, 377 \\
PL &, 212 &, 095 &, 221 & 2,237 &, 029 \\
\hline
\end{tabular}

a. Dependent Variable: KN

Sumber: hasil output SPSS versi 23, data diolah 
POINT Vol. 1, No. 2, Des 2020

Persamaan regresinya sebagai berikut:

$Y=a+b 1 E M+b 2 P R+b 3 P L$

Sehingga persamaan regresinya adalah:

Keputusan $=10,762+0,485$ Ekuitas Merek + 0,113 Promosi $+0,212$ Pelayanan

Keterangan :

$\begin{array}{ll}\mathrm{Y} & =\text { Keputusan Nasabah } \\ \mathrm{a} & =\text { Konstant } \\ \mathrm{b} 1 \mathrm{~b} 2 \mathrm{b3} & =\text { Koefisien Regresi Linear } \\ \text { Berganda } & \\ \mathrm{EM} & =\text { Ekuitas Merek } \\ \mathrm{PR} & =\text { Promosi } \\ \mathrm{PL} & =\text { Pelayanan }\end{array}$

Persamaan regresi diatas dapat dijelaskan sebagai berikut:

a) Konstanta sebasar 10,762 artinya apabila variabel Ekuitas Merek, Promosi dan Pelayanan dianggap konstan atau 0 maka keputusan nasabah menggunakan Bank Syariah di Pasar Sangkumpal Bonang Padang Sidimpuan sebesar 10,762 satuan.

b) Nilai koefisien Ekuitas Merek sebesar 0,485 artinya bahwa setiap peningkatan ekuitas merek $1 \%$ maka keputusan nasabah naik sebesar 0,485 dengan nilai 10,762 $+0,485=11,247$, maka naik $=11,247 \times 100 \%=11,247$ dengan asumsi variabel independen lain nilainya tetap.

c) Nilai koefisien Promosi sebesar 0,113 artinya bahwa setiap peningkatan promosi 1\% maka keputusan nasabah naik sebesar 0,113 dengan nilai $10,762+0,113$ $=10,875$ maka naik $=10,875 \times$ $100 \%=10,875$ dengan asumsi variabel independen lain nilainya tetap.

d) Nilai koefisien Pelayanan sebesar 0,212 artinya bahwa setiap peningkatan pelayanan $1 \%$ maka keputusan nasabah naik sebesar 0,212 dengan nilai $10,762+0,212$ $=10,984$ maka naik $=10,984 x$ $100 \%=10,984$ dengan asumsi variabel independen lain nilainya tetap.

4. Uji Hipotesis

a) Uji Parsial (Uji t)

Uji t pada dasarnya menunjukkan seberapa jauh pengaruh satu variable penjelas secara individual dalam menerangkan variasi variable terikat, nilai ttabel sebesar 2,07961.

Tabel 12

Hasil Olah Data SPSS Versi 23 Uji t

Coefficientsa

\begin{tabular}{|c|r|r|r|r|r|}
\hline \multirow{2}{*}{ Model } & \multicolumn{2}{|c|}{$\begin{array}{c}\text { Unstandardized } \\
\text { Coefficients }\end{array}$} & $\begin{array}{c}\text { Standardized } \\
\text { Coefficients }\end{array}$ & & \\
\cline { 2 - 4 } & \multicolumn{1}{c|}{$\mathrm{B}$} & Std. Error & \multicolumn{1}{|c|}{ Beta } & \multicolumn{1}{c|}{$\mathrm{t}$} & Sig. \\
\hline (Constant) & 10,762 & 5,326 & & 2,021 &, 048 \\
EM &, 485 &, 095 &, 523 & 5,120 &, 000 \\
PR &, 113 &, 128 &, 089 &, 890 &, 377 \\
PL &, 212 &, 095 &, 221 & 2,237 &, 029 \\
\hline
\end{tabular}


a. Dependent Variable: KN

Sumber: hasil output SPSS versi 23, data diolah

Hasil pengujian variabel-variabel penelitian secara parsial adalah sebagai berikut:

1) Pengaruh Ekuitas Merek terhadap Keputusan nasabah Nilai thitung variabel Ekuitas Merek yaitu 5,120. Jadi thitung $>$ ttabel $(5,120>1,29471)$ sehingga Ha1 diterima artinya ekuitas merek secara parsial berpengaruh terhadap keputusan nasabah.

2) Pengaruh Promosi terhadap Keputusan nasabah

Nilai thitung variabel harga yaitu 0,890 . Jadi thitung < ttabel $(0,890<1,29471)$ sehingga $\mathrm{Ha} 2$ ditolak, artinya promosi secara parsial tidak berpengaruh terhadap keputusan nasabah.

3) Pengaruh Pelayanan terhadap Keputusan nasabah

Nilai thitung variabel promosi yaitu 2,237. Jadi thitung < ttabel $(2,237<1,29471)$ sehingga $\mathrm{Ha} 3$ diterima, artinya pelayanan secara parsial berpengaruh terhadap keputusan nasabah.

b) Uji Koefisien Regresi Secara Simultan (Uji F)

Uji $F$ bertujuan untuk menunjukkan apakah semua variable independen yang dimasukkan ke dalam model secara simultan atau bersamasama mempunyai pengaruh terhadap variable dependen.

Tabel 13

Hasil Olah Data SPSS Versi 23 Uji F

\begin{tabular}{|c|c|r|r|l|l|}
\hline & Sum of & & Mean & & \\
Model & Squares & Df & Square & F & Sig. \\
\hline Regression & 268,626 & 3 & 89,542 & 15,717 &, $000 \mathrm{~b}$ \\
Residual & 364,609 & 64 & 5,697 & & \\
Total & 633,235 & 67 & & & \\
\hline
\end{tabular}

a. Dependent Variable: KN

b. Predictors: (Constant), PL, PR, EM

Dari hasil output di atas Fhitung $(15,717)>$ Ftabel $(2,17)$ dan signifikansi $<0,1$ $(0,000<0,1)$ maka HO ditolak jadi dapat disimpulkan bahwa Ekuitas Merek, Promosi dan Pelayanan secara bersama-sama berpengaruh terhadap Keputusan Nasabah menggunakan Bank Syariah di Pasar Sangkumpal Bonang Padangsidimpuan.

\section{PENUTUP}

\section{Kesimpulan}

Berdasarkan hasil analisis data dan pembahasan mengenai pengaruh Ekuitas Merek, Promosi dan Pelayananterhadap variabel keputusan nasabah menggunakan Bank Syariah di Pasar Sangkumpal Bonang Padangsidimpuan maka dapat ditarik beberapa kesimpulan sebagai berikut:

1. Terdapat pengaruh yang positif signifikan antara variabel Ekuitas merek terhadap Keputusan Nasabah menggunakan Bank 
Syariah di Pasar Sangkumpal Bonang Padangsidimpuan.

2. Tidak terdapat pengaruh yang positif signifikan antara variabel Promosi terhadap Keputusan Nasabah menggunakan Bank Syariah di Pasar Sangkumpal Bonang Padangsidimpuan.

3. Terdapat pengaruh yang positif signifikan antara variabel Pelayanan terhadap Keputusan Nasabah menggunakan Bank Syariah di Pasar Sangkumpal Bonang Padangsidimpuan.

4. Terdapat pengaruh yang positif signifikan secara simultan antara variabel Ekuitas Merek, Promosi dan Pelayanan terhadap Keputusan Nasabah menggunakan Bank Syariah di Pasar Sangkumpal Bonang Padangsidimpuan.

\section{Saran}

Semoga adanya peningkatan pelayanan perbankan syariah ke depannya agar ada penambahan nasabah.

\section{DAFTAR PUSTAKA}

Adiwarman Karim, Bank Islam, Jakarta: Raja Grafindo Persada, 2007.

Ali Hasan, Marketing Bank Syariah, Bogor: Gholia Indonesia, 2010.

Bambang Prasetyo dan Lina Miftahul Jannah, Metode Penelitian Kuantitatif, Bandung: Raja Grafindo Persada, 2005.

Danang Sutoyo, Dasar-Dasar Manajemen Pemasaran, Yogyakarta: CAPS, 2014.
Duane E. Knapp, The Brand Mindset, Yogyakarta: Andi, 2002.

Dwi Priyatno, Mandiri Belajar SPSS, Yogyakarta: Mediakom, 2008.

Dwi Priyatno, SPSS 22: Pengolahan Data Terpraktisi, Yogyakarta: ANDI, 2014.

Dwi Suyikno, Kamus Besar Ekonomi Islam, Yogyakarta: Total Media, 2009.

http://okepasid. Blogspot.com/2018/Pasar terbesar di Tapanuli Selatan, diakses pada 09 november 2019 pukul 13:00 Wib.

James F. Angel dkk, Perilaku Konsumen, Jakarta: Bina Rupa Aksara, 1995.

Kasmir, Manajemen Perbankan, Jakarta: Rajawali, 2008.

Pemasaran Bank, Jakarta: Kencana, 2010.

Leon Schiffman dan Leslie Lazar Kanuk, Perilaku Konsumen (Terjemahan)Adi Mulana, Wibi Hardani, Jakarta: Indeks, 2007.

Perilaku Konsumen, dan Diterjemahkan dari "Concumre Behavior" Oleh Zoelkifli Kasip Indonesia: PT. Macanan Jaya Cemerlang, 2008.

Hasibuan, Malayu S.P, Dasar-Dasar Perbankan, Jakarta: Bumi Aksara, 2009.

Maman Abdurrahman \& Sambas Ali Muhidin, Panduan Praktisi Memahami Penelitian, Bandung: Pustaka Setia, 2011.

Marison, Metode Penelitian Survey, Jakarta: Kencana, 2012.

Periklanan: Komunikasi Pemasar Terpadu, Jakarta: Kencana, 2010.

Mudrajad kuncoro, Metode Riset untuk Bisnis dan ekonomi, Jakarta: Erlangga, 2009. 
Muhammad Syafii Antonio, Bank Syariah dari Teori ke Praktek, Jakarta: Gema Insani, 2001.

Muhammad Teguh, Metodologi Penelitian Ekonomi, Jakarta: PT. Raya Grafindo Persada, 2005.

M. Mursid, Manajemen Pemasaran, Jakarta: PT. Bumi Aksara, 2008.

M. Nur Rianto Al-Arif, Dasar-Dasar Pemasaran Bank Syariah, Bandung: Alfabeta, 2010.

Richard L. Daft, "Manajemen" diterjemahkan dari "Manajemen" oleh Edward Tanujaya dan Shirly Tiolina,Jakarta: Salemba Empat, 2003.

Riduan, Skala Pengukuran Variabel-Variabel Penelitian, Bandung: ALFABETA, 2010.

Setiawan dan Dwi Endah Kusrini, Ekonometrika, Yogyakarta: ANDI, 2010.
Simamora Henry, Manajemen Pemasaran Internasional, Jakarta: Salemba Empat, 2000.

Siregar Sofyan, Statistika Deskriptif untuk Penelitian, Jakarta: PT. Raja Grafindo Persada, 2010.

Sugiyono,Metode Penelitian Kuantitatif, Kualitatif, dan R\&D, Bandung: Alfabeta, 2010.

,Metode Penelitian, Bisnis, Bandung: Alfabeta, 2012.

Metode Penelitian Pendidikan: Pendekatan Kuantitatif, Kualitatif dan R\&D, Bandung: Alfabeta, 2013.

Sutan Remi Syadeini, Perbankan Syariah, Produk-Produk dan Aspek-Aspek Hukumnya, Jakarta: Kencana, 2014.

Syauqi Ahmad Dunya, Sistem Ekonomi Islam, Jakarta: Fikaha Aneska, 1994. 